\title{
The Applicability of Commonly Used Severity of Illness Scores to Tropical Infections in Australia
}

\author{
Kris Salaveria ${ }^{1}$, Simon Smith², Yu-Hsuan Liu', Richard Bagshaw ${ }^{2}$, Markus Ott ${ }^{1}$, Alexandra Stewart ${ }^{3}$, Matthew Law ${ }^{4}$, \\ Angus Carter ${ }^{1,5}$, and Josh Hanson ${ }^{2,4^{*}}$ \\ ${ }^{1}$ Department of Intensive Care, Cairns Hospital, Cairns, Queensland, Australia; ${ }^{2}$ Department of Medicine, Cairns Hospital, Cairns, Queensland, \\ Australia; ${ }^{3}$ Infectious Diseases Unit, Western Health, Victoria, Australia; ${ }^{4}$ Kirby Institute, University of New South Wales, Sydney, Australia; \\ ${ }^{5}$ James Cook University, Cairns Campus, Cairns, Queensland, Australia
}

\begin{abstract}
Many patients with leptospirosis, melioidosis, and rickettsial infection require intensive care unit (ICU) admission in tropical Australia every year. The multi-organ dysfunction associated with these infections results in significantly elevated severity of illness (SOI) scores. However, the accuracy of these SOI scores in predicting death from these tropical infections is incompletely defined. This retrospective study was performed at Cairns Hospital, a tertiary-referral hospital in tropical Australia. All patients admitted to ICU with laboratory-confirmed leptospirosis, melioidosis, and rickettsial disease between January 1, 1999 and June 30, 2020, were eligible for the study. The ability of Acute Physiology and Chronic Health Evaluation (APACHE) II, APACHE III, Simplified Acute Physiology Scores (SAPS) II, and Sequential Organ Failure Assessment (SOFA) scores to predict death before ICU discharge was evaluated. Overall, 18 (12.1\%) of the 149 included patients died: 15/74 (20.3\%) with melioidosis, 2/54 (3.7\%) with leptospirosis and 1/21 (4.8\%) with rickettsial disease. However, the APACHE II, APACHE III, SAPS II, and SOFA scores significantly overestimated the casefatality rate of all the infections; the disparity between the predicted and observed mortality was most marked in the cases of leptospirosis and rickettsial disease. Commonly used SOI scores significantly overestimate the case-fatality rate of melioidosis, leptospirosis, and rickettsial infections in Australian ICU patients. This may be at least partly explained by the unique pathophysiology of these infections, particularly leptospirosis and rickettsial disease. However, SOI scores may still be useful in facilitating the comparison of disease severity in clinical trials that examine patients with these pathogens.
\end{abstract}

\section{INTRODUCTION}

Sepsis causes approximately $20 \%$ of deaths globally and is more common in tropical low- and middle-income countries (LMIC). ${ }^{1-3}$ The incidence of sepsis in tropical Australia is also far greater than in the temperate regions of the country. ${ }^{4,5}$ Most presentations with sepsis in tropical Australia are due to pathogens-such as Staphylococcus aureus or Escherichia coli-that also cause disease in temperate settings. ${ }^{4,6}$ However, several classical tropical pathogens are also encountered. These include Burkholderia pseudomallei (which causes melioidosis), spirochetes of the genus Leptospira (which cause leptospirosis) and the rickettsiae Orientia tsutsugamushi and Rickettsia australis (which cause scrub typhus and Queensland tick typhus [QTT] respectively). ${ }^{4,7-9}$

These tropical pathogens can lead to multi-organ involvement with concurrent-sometimes dramatic-derangement in clinical and laboratory indices. ${ }^{10-12}$ This results in significant elevation of the severity of illness (SOI) scores that are routinely calculated to estimate mortality risk in the critical care population. ${ }^{13}$ While SOI scores have no role in the management of individual patients, they permit quantitative assessment of an intensive care unit's (ICU) performance, allowing comparison between institutions. Severity of illness scores are also used in clinical trials to measure disease severity, facilitating comparison within and between cohorts, providing a benchmark to monitor the success of interventions. ${ }^{14}$

Globally, the most commonly used SOI scores are the Acute Physiology and Chronic Health Evaluation (APACHE) scores, ${ }^{15,16}$ the Sequential Organ Failure Assessment (SOFA) score, ${ }^{17}$ and the Simplified Acute Physiology Scores (SAPS). ${ }^{18}$ These SOI scores are neither organ nor disease

*Address correspondence to Josh Hanson, Kirby Institute, University of New South Wales, Sydney, NSW, Australia 2052. E-mail: jhanson@kirby.unsw.edu.au specific, but they are strong predictors of mortality in patients admitted to the ICU with sepsis. ${ }^{19-23}$ However, there are limited data about the predictive ability of SOI scores in patients with melioidosis, leptospirosis, and rickettsial diseases. ${ }^{24,25}$ This is important as the case-fatality rate of these pathogens can vary significantly in different parts of the world. ${ }^{3}$ It can be challenging to determine whether this is due to differences in patient demographics and comorbidities, to differences in the pathogens' virulence, or simply to disparities in access to optimal care. ${ }^{24,26}$ The routine use of SOI scores in studies of patients with these infections could standardize assessment of disease severity, enabling multi-center trials evaluating the efficacy of different management strategies of these important pathogens.

The region of Far Northern Queensland in tropical Australia has the highest incidence of leptospirosis in Australia and has a significant-and increasing-incidence of melioidosis and rickettsial disease. ${ }^{8,9,27}$ Given the local-and globalburden of life-threatening sepsis from these pathogens, this study was performed to determine the ability of commonly used SOI scores to predict death in patients with these infections. ${ }^{28-30}$ This might validate the use of these scores in the comparison of cohorts of patients affected by these pathogens in different parts of the world.

\section{METHODS}

This retrospective study was performed at Cairns Hospital, a 531-bed tertiary hospital located in Far North Queensland, tropical Australia. The hospital is the main referral center for a population of approximately 280,000 people who live across an area of $380,000 \mathrm{~km}^{2}$, in the Northeastern tip of Australia.

Adults ( $\geq 18$ years old) admitted to the Cairns ICU between January 1, 1999 and June 30, 2020, with a laboratory- 
confirmed diagnosis of melioidosis, leptospirosis, or rickettsial infection were included in the study. Patients were identified using the hospital's electronic pathology reporting system. A case of melioidosis was defined as a positive culture of $B$. pseudomallei. The Australian case definition for confirmed leptospirosis - isolation of pathogenic Leptospira, a 4-fold or greater rise in Leptospira agglutination titer between acute and convalescent phase sera or a single Leptospira micro agglutination titer $\geq 400$ supported by a positive enzyme-linked immunosorbent assay $\operatorname{lgM}$ result-was used for cases of leptospirosis. ${ }^{31}$ Rickettsial infection was diagnosed if there was a clinical diagnosis of $O$. tsutsugamushi or $R$. australis infection accompanied by a positive polymerase chain reaction ( $P C R$ ), a 4-fold rise in titers of paired serological samples (confirmed infection) or a single serological titer $\geq 128$ with a clinically compatible syndrome (two or more of fever, rash, eschar, myalgia, or headache with no convincing alternative diagnosis) (probable infection). ${ }^{12}$

Demographic, clinical, and laboratory data were collected from electronic and paper medical records. The study's primary endpoint was death before ICU discharge. The APACHE II, APACHE III, SOFA, and SAPS II scores were calculated using the worst values in the first 24 hours of admission. ${ }^{15-18}$ The scores and associated risk of death was provided by the Australian New Zealand Intensive Care Society (ANZICS) database. Cases that occurred prior to the establishment of the ANZICS database were calculated manually using online calculators. ${ }^{32-34}$

Severity of illness scores and case-fatality rates of other ICU-based studies of patients with melioidosis, leptospirosis, and rickettsial disease were collected for comparison. An electronic search was performed using MEDLINE ${ }^{\circledR}$ (1999-Present), PubMed (1999-Present), and Google Scholar. The search strategy included the terms "intensive care," "disease severity score," "severity of illness score" "prediction score," the names of the individual scores, the diseases, and their etiological agents. The reference lists of the articles were also reviewed. Pediatric series, case series with $<20$ patients and studies where the ICU status of the patients was incompletely defined were excluded.

To compare the performance of SOI scores in the melioidosis, leptospirosis, and rickettsial disease with their performance in patients with sepsis due to other infections, the APACHE III scores of other patients admitted to the Cairns Hospital ICU with a primary admission diagnosis of sepsis (APACHE III-J diagnostic codes 501-504: nonurinary sepsis, urinary sepsis, nonurinary sepsis with shock, and urinary sepsis with shock respectively) were also examined. The APACHE III scores of the patients with other causes of sepsis, their expected risk of death, and their observed case-fatality rate were provided by the ANZICS database.

\section{STATISTICAL ANALYSIS}

Data were de-identified, entered into an electronic database (Microsoft Excel), and analyzed using statistical software (Stata version 14.2). Groups were analyzed using the Kruskal-Wallis, the $\chi^{2}$ tests, and Fisher's exact test, where appropriate. The scores' ability to predict death was determined by comparing the scores' predicted mortality-stratified into quartiles - with the observed case-fatality rate.

Ethics statement Ethics approval was provided by the Far North Queensland Human Research Ethics Committee (HREC/2020/QCH/64424-1442). As the data were retrospective and de-identified, the Committee waived the requirement for informed consent.

\section{RESULTS}

Patient characteristics. A total of 149 cases were identified: this included $74(49.7 \%)$ cases of melioidosis, 54 (36.2\%) cases of leptospirosis, and 21 (14.1\%) cases of rickettsial disease (12 cases of scrub typhus and nine cases of QTT). The demographics of the patients, the ICU support they received, and their case-fatality rates are presented in Table 1.

Case-fatality rate of predictive ability of severity of illness scoresV. Overall, patients with melioidosis had a higher case-fatality rate $(15 / 74(20.3 \%)$ than those with leptospirosis $(2 / 54$ [3.7\%], $P=0.007)$; the difference between the case-fatality rate of patients with melioidosis and those with rickettsial disease $(1 / 21$ [4.8\%], $P=0.11)$ did not reach statistical significance. In the first 5 years of the study period, $5 / 8(62.5 \%)$ patients with melioidosis died compared with $3 /$ $30(10.0 \%)$ in the last 5 years $(P=0.005)$. The small number of fatal cases of leptospirosis and rickettsial disease during the study precluded analysis of the trend in the case-fatality rate of these infections over time (Figure 1).

However, regardless of the pathogen, all four SOI scores overestimated the patients' case-fatality rate (Table 2, Figures 2-5). The disparity between the predicted and the observed case-fatality rate was most marked in the patients with leptospirosis and rickettsial disease.

Comparison with other patients admitted to ICU with sepsis. The APACHE III scores of patients admitted to the ICU with melioidosis, leptospirosis, and rickettsial disease were compared with those of patients with sepsis due to other pathogens. The APACHE III scores also overestimated the case-fatality rates of patients admitted to the hospital's ICU with the other pathogens: the mean (95\% CI) APACHE III score of these 2,092 patients was 75 (74-76). Their overall mean $(95 \%)$ predicted case-fatality rate was $32(31-24 \%)$ compared with the observed case-fatality rate of $301 / 2092$ (14\%). The degree to which the APACHE III score overestimated the case-fatality rate among these 2,092 patients with

TABLE 1

Selected demographics, supportive care, and outcomes of the cohort stratified by infection

\begin{tabular}{|c|c|c|c|c|c|c|c|}
\hline & Number & Male $\mathrm{n}(\%)$ & Age (mean $[95 \% \mathrm{Cl}]$ ) & Mechanical ventilation, $\mathrm{n}(\%)$ & RRT, n (\%) & Vasopressor support, n (\%) & Case-fatality rate, $\mathrm{n}(\%)$ \\
\hline Melioidosis & 74 & $52(70.3)$ & $55(52-58)$ & $48(64.9 \%)$ & $23(31.1 \%)$ & $61(82.4 \%)$ & $15(20.3 \%)$ \\
\hline Leptospirosis & 54 & 47 (87.0) & $47(42-52)$ & $25(46.3 \%)$ & 19 (35.2\%) & $34(63.0 \%)$ & $2(3.7 \%)$ \\
\hline Rickettsial infection & 21 & $11(52.4)$ & $51(44-58)$ & $10(47.6 \%)$ & $5(23.8 \%)$ & $13(61.9 \%)$ & $1(5.3 \%)$ \\
\hline Total & 149 & $110(73.8)$ & $51(49-54)$ & $83(55.7 \%)$ & $46(30.9 \%)$ & $108(72.5 \%)$ & $18(12.1 \%)$ \\
\hline
\end{tabular}

Association between severity of illness scores and outcome. 
A
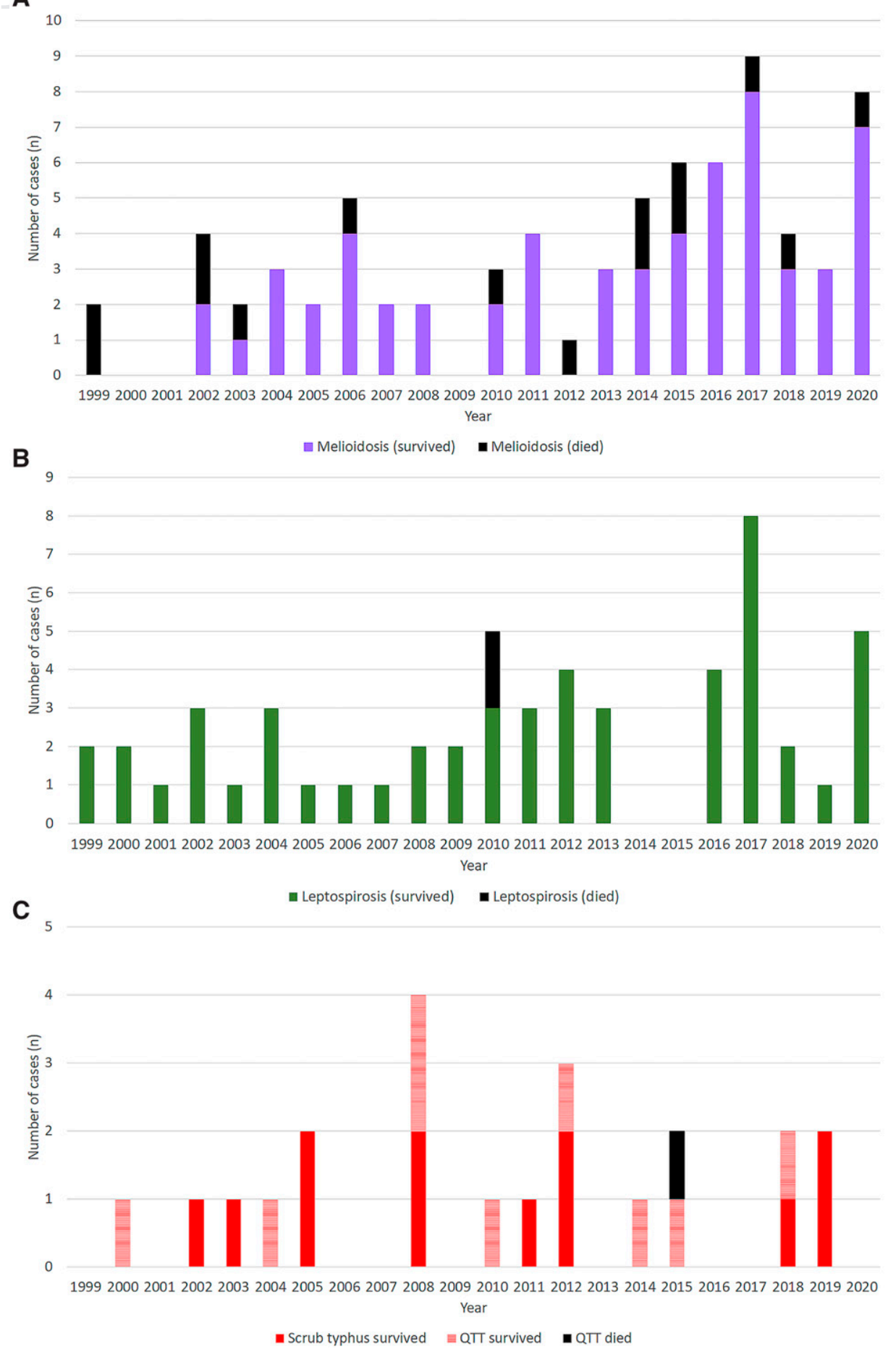

FIGURE 1. This figure appears in color at www.ajtmh.org.

sepsis - while similar to that seen in patients with melioidosis-was far greater degree in the cases of leptospirosis and rickettsial disease (Figure 6).

\section{DISCUSSION}

Commonly used SOI scores significantly overestimated the case-fatality rate of patients admitted to ICU with melioidosis, leptospirosis, and rickettsial disease at this center in tropical Australia. This is likely to be at least partly linked to the distinctive pathophysiology of these infectionsparticularly leptospirosis and rickettsial disease-whose multi-organ involvement results in significant derangement of multiple parameters, inflating the scores, and exaggerating the risk of death. This adds to other limitations of SOI scores, whose performance tend to deteriorate over time. ${ }^{35,36}$ Furthermore, SOI scores perform best in the population in which the score was originally derived and as all 
TABLE 2

Severity of illness scores' prediction of case-fatality rate compared with the observed case-fatality rate of patients admitted to Cairns Hospital ICU between 1999 and 2020

\begin{tabular}{|c|c|c|c|c|}
\hline Disease & Observed case-fatality rate & Severity of illness score & Mean $(95 \% \mathrm{Cl})$ score & Mean $(95 \% \mathrm{Cl})$ predicted case-fatality rate (\%) \\
\hline \multirow[t]{4}{*}{ Melioidosis } & $15 / 74(20.2 \%)$ & APACHE II & $22(20-24)$ & $44.8(39.5-50.0)$ \\
\hline & & APACHE III & $82(75-90)$ & $37.6(31.4-43.7)$ \\
\hline & & SAPS2 & $43(38-48)$ & $34.5(27.2-41.7)$ \\
\hline & & SOFA & $9(8-10)$ & $36.0(28.1-44.0)$ \\
\hline \multirow[t]{4}{*}{ Leptospirosis } & 2/54 (3.7\%) & APACHE II & $20(17-23)$ & $38.6(31.0-46.3)$ \\
\hline & & APACHE III & $76(66-87)$ & $33.7(25.4-42.0)$ \\
\hline & & SAPS2 & $37(30-43)$ & $30.0(20.9-39.3)$ \\
\hline & & SOFA & $12(10-14)$ & $53.0(43.4-62.6)$ \\
\hline \multirow[t]{4}{*}{ Rickettsial disease } & $1 / 21(4.8 \%)$ & APACHE II & $20(16-23)$ & $36.0(26.8-45.1)$ \\
\hline & & APACHE III & $79(66-93)$ & $33.9(21.7-46.1)$ \\
\hline & & SAPS2 & $39(31-48)$ & $29.0(16.3-41.6)$ \\
\hline & & SOFA & $8(6-10)$ & $29.0(15.3-42.7)$ \\
\hline
\end{tabular}

APACHE = Acute Physiology and Chronic Health Evaluation; ICU = intensive care unit; SAPS = Simplified Acute Physiology Scores; SOFA = Sequential Organ Failure Assessment.

four scores were derived in well-resourced referral ICUs in large cities in temperate regions, they are likely to be less applicable to patients in the ICUs in locations where melioidosis, leptospirosis, and rickettsial diseases are more commonly seen. ${ }^{15-18,25,37,38}$

The design of the various SOI scores will tend to accentuate different physiological derangements. A patient's serum creatinine, their oxygen requirement, their bilirubin, and their platelet count, for example, are used to determine four of the SOFA score's six components. ${ }^{17}$ The systemic inflammatory response seen in leptospirosis particularly affects the microcirculation and in severe cases can lead to renal failure, respiratory failure, abnormal liver function tests, and thrombocytopenia; it may be unsurprising to see that the patients with leptospirosis in this cohort had the highest SOFA scores. $^{9,39}$ However, this resulted in a significant overestimation of the case-fatality rate in the cohort, which the SOFA score predicted to be 53\% (95\% Cl: 43-63\%) compared with the observed figure of $3.7 \%$. A similar pattern was observed in patients suffering from the rickettsial diseases of scrub typhus and QTT, conditions where endothelial infection and inflammation also commonly result in thrombocytopenia and hepatic and renal impairment. ${ }^{40,41}$ The SOFA scores of the patients with rickettsial disease predicted a case-fatality rate in the cohort of $29 \%(95 \% \mathrm{Cl}$ : $15-43 \%)$ compared with the observed figure of $4.8 \%$.

The disparity between the predicted and observed casefatality rate among patients with leptospirosis and rickettsial disease may be related to the tendency of cases with severe disease to involve multiple systems concurrently resulting in-sometimes dramatic-derangement in clinical and laboratory indices, as opposed to other causes of critical illness where fewer organ systems may be involved. ${ }^{42}$ Furthermore, although thrombocytopenia and derangement of liver function tests are common in cases of severe leptospirosis and rickettsial disease, neither have strong independent prognostic utility in either condition. ${ }^{43-46}$

Although patients admitted to ICU with melioidosis also commonly have multi-organ involvement, their clinical presentation has a closer resemblance to the sepsis caused by more familiar bacterial pathogens. ${ }^{47}$ Patients present most frequently with pneumonia, while $74 \%$ have septic shock. ${ }^{10}$ As the SOI scores were derived predominantly in North American and European referral centers-where pneumonia
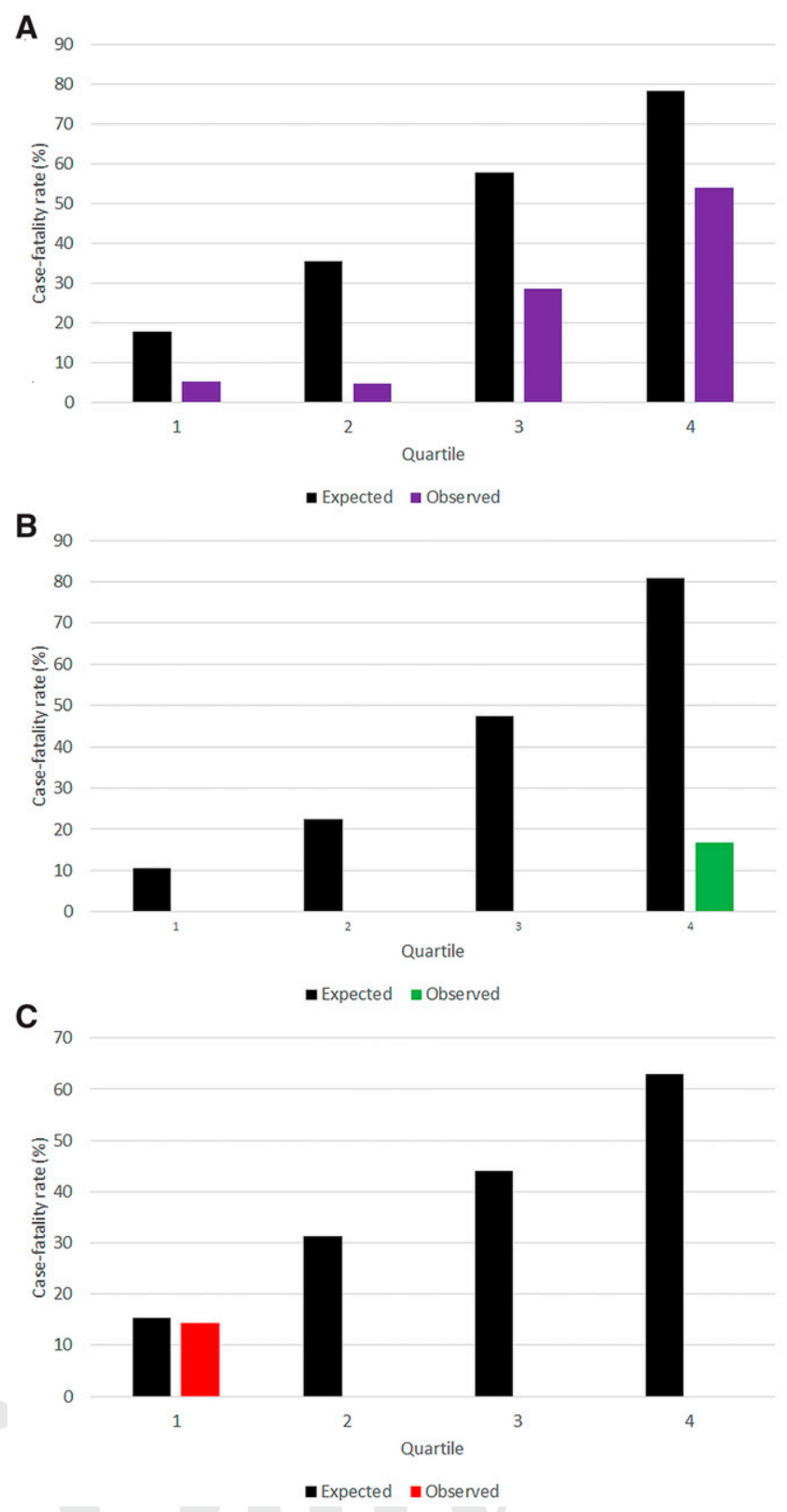

FIGURE 2. This figure appears in color at www.ajtmh.org. 
A
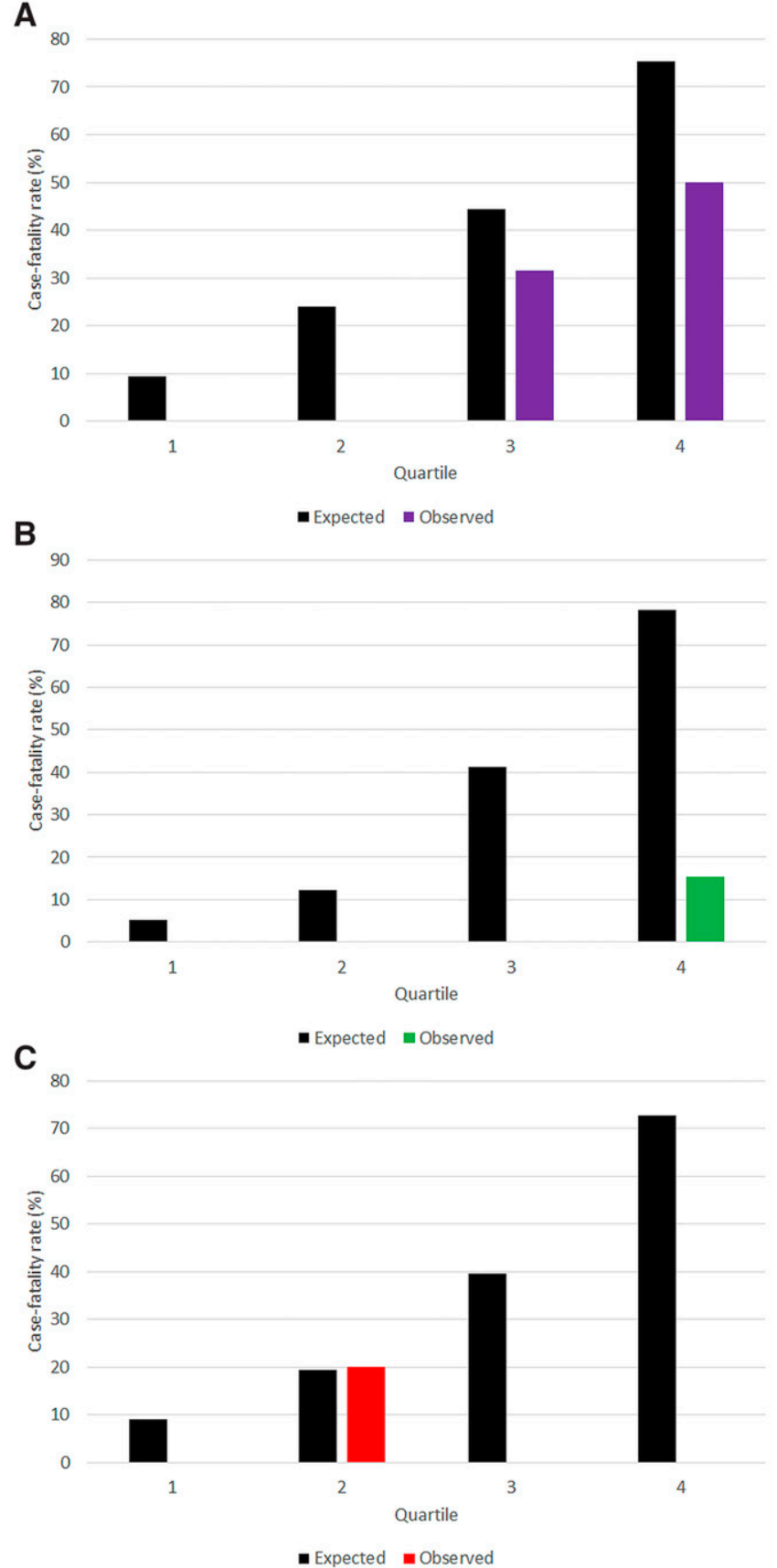

FIGURE 3. This figure appears in color at www.ajtmh.org.

and septic shock are a common cause of ICU admissionthis may explain why there was less discrepancy between the SOI scores' predicted mortality in patients with melioidosis and their observed case-fatality rate.

The specific issues highlighted with using SOI scores in the patients with the tropical infections in this cohort, add to the scores' well-recognized general limitations. Severity of illness scores are almost universally derived and validated in general ICU patients in well-resourced, metropolitan referral centers in Europe and North America, their predictive ability has been shown to vary in different geographical regions. ${ }^{48,49}$ The scores' performance also differs in different patient populations. The APACHE II score, for instance,
A
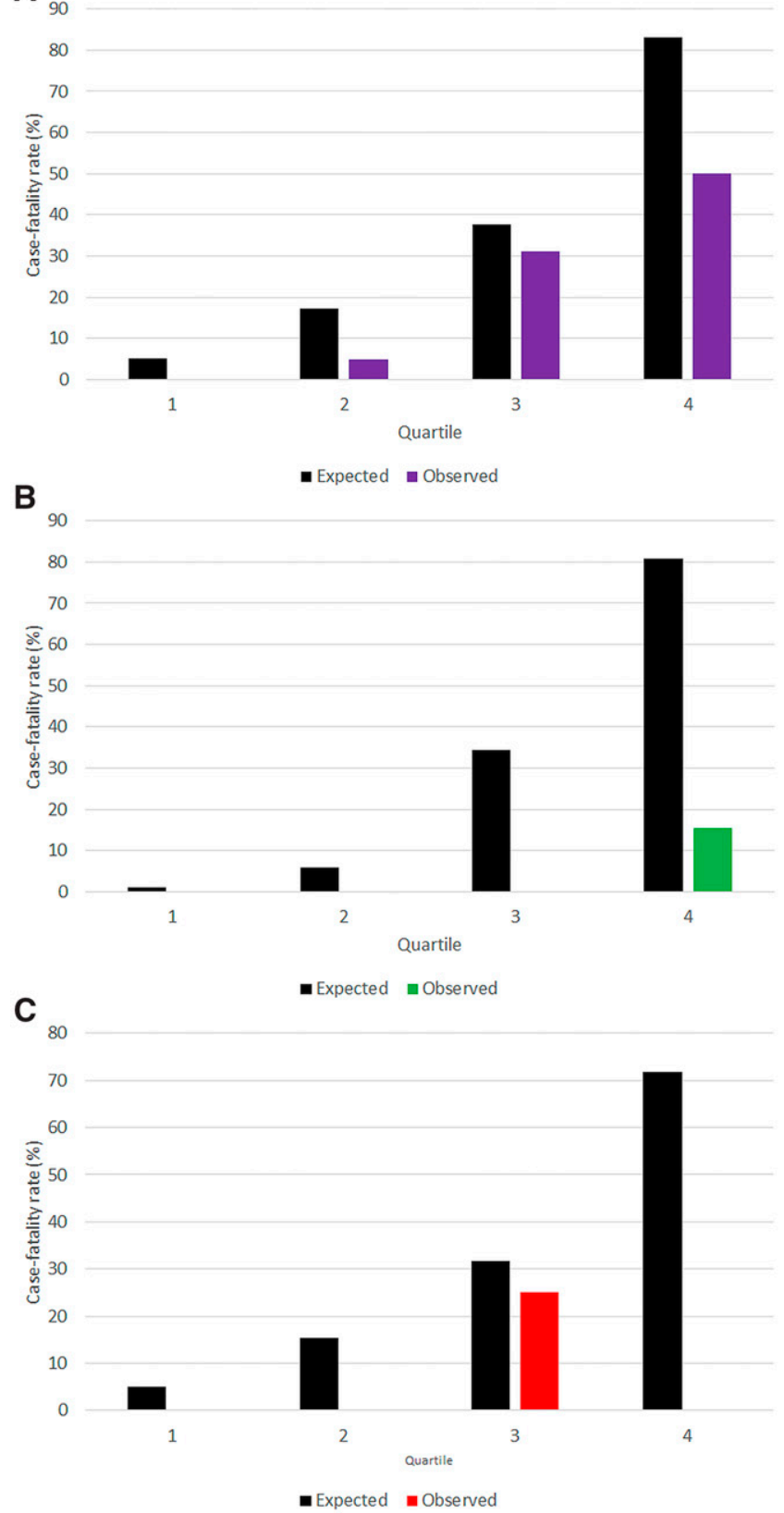

FIGURE 4. This figure appears in color at www.ajtmh.org.

underestimated mortality in patients with severe acute respiratory syndrome coronavirus 2 (SARS-CoV-2), ${ }^{42}$ while overestimating mortality in obstetric patients. ${ }^{50}$ Meanwhile, patients transferred from other hospitals have a case-fatality rate that is higher than predicted by the APACHE II score and this lead time bias may be seen in other SOI scores. ${ }^{37}$ Finally, with improvements in critical care, the performance of SOI scores tends to deteriorate over time, the APACHE and SAPS scores have therefore been revised to improve their calibration and discrimination, although these newer iterations are more complex to calculate. ${ }^{51,52}$ This is relevant because a SOI score's ease of use is an important virtue, particularly in resource-limited settings where it can be challenging to collect many of the variables. ${ }^{25,36}$ It was notable that in this cohort the APACHE III score also overestimated 
A

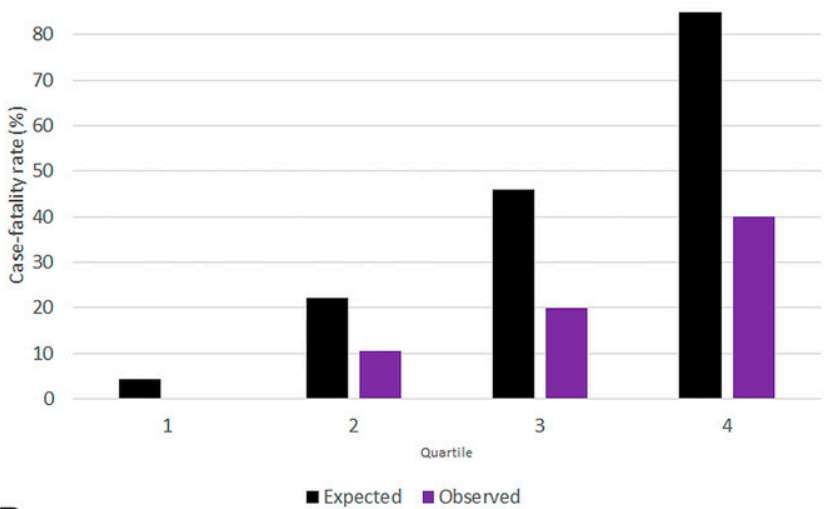

B
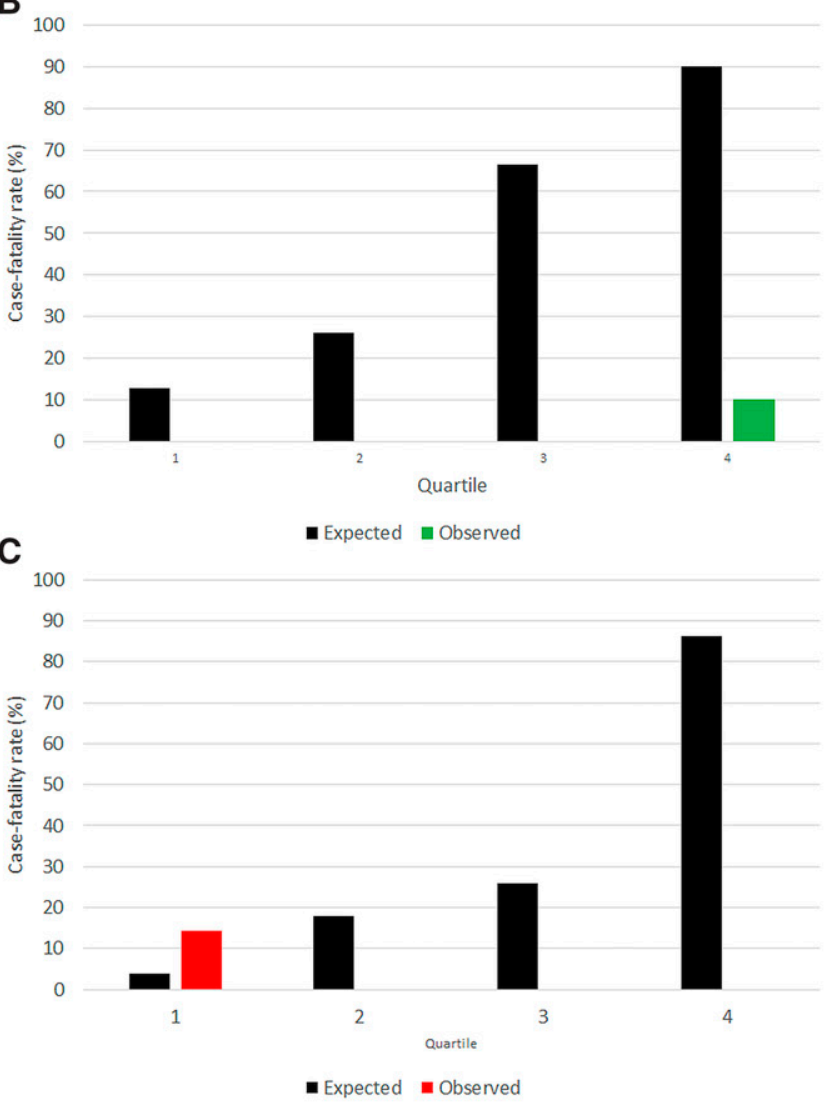

FIGURE 5. This figure appears in color at www.ajtmh.org.

the case-fatality rate of patients admitted to the Cairns Hospital ICU-which has a similar SMR to comparable ICUs in Australia-with more common causes of sepsis (Figure 6, Supplemental Figure 1).

However, while acknowledging these limitations and deficiencies, there may still be a role for SOI scores in stratifying disease severity in clinical trials of patients with melioidosis, leptospirosis, and rickettsial diseases. These pathogens have a global distribution and there is a marked geographic disparity in the case-fatality rate of each of the infections (Tables 3-5). ${ }^{28,29,76}$ For example, a cohort of patients with severe leptospirosis managed in well-resourced ICUs in France had a median (IQR) SAPS II score of 40 (28-58) and a case-fatality rate of $8.8 \% \cdot{ }^{56}$ Meanwhile, a cohort of patients with severe leptospirosis managed in a single ICU on
A
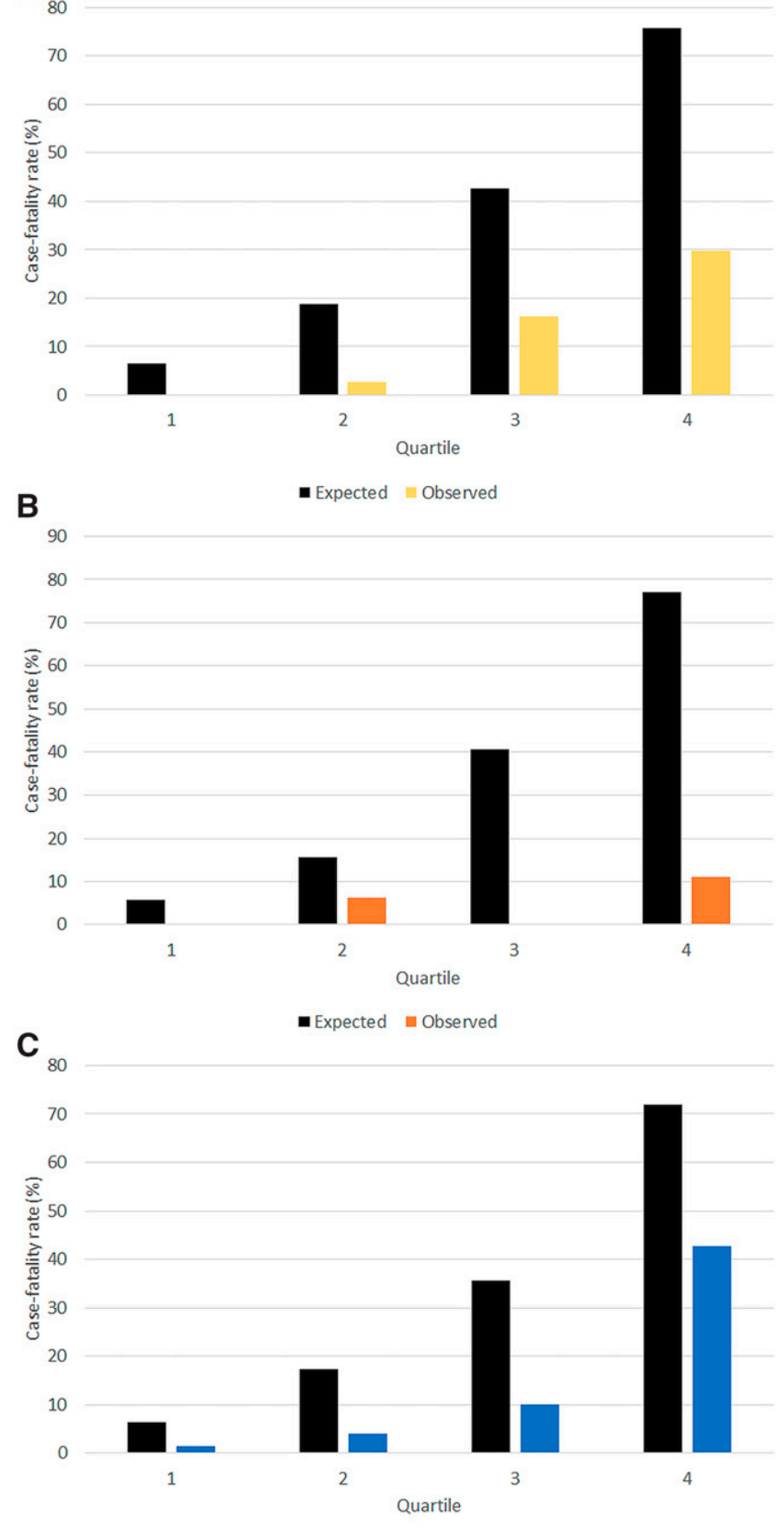

- Expected abserved

FIGURE 6. This figure appears in color at www.ajtmh.org.

Réunion Island-which also had access to advanced supportive care including extracorporeal membrane oxygenation-had a median (IQR) SAPS II score of 38 (27-50) and a case-fatality rate of $5.9 \% .{ }^{55}$ In contrast, in a Moroccan cohort with lower SAPS II scores $(24 \pm 11.5)$, the case-fatality rate was greater at $23 \%{ }^{58}$ The case-fatality rate was even higher in series from Brazil, India, and Sri Lanka, but SOI scores were not reported in most of these studies (Table 3). ${ }^{60-64,77}$ There is a similar geographic disparity in outcomes in cohorts of patients with melioidosis and rickettsial diseases in different jurisdictions (Tables 4 and 5). While these differences are almost certainly-at least partly-explained by access to optimal supportive care, which varies enormously between- 
TABLE 3

Severity of illness scores and case-fatality rates of patients with leptospirosis, admitted to the ICU in other case series

\begin{tabular}{|c|c|c|c|c|c|c|c|c|c|}
\hline Study & Study Period & Country & Setting & Cases & APACHE II & APACHE III & SAPS2 & SOFA & $\begin{array}{c}\text { ICU case- } \\
\text { fatality Rate \% }\end{array}$ \\
\hline Cedano et al. ${ }^{53}$ & 2010-2016 & Colombia & Single ICU & 30 & Not reported & Not reported & $\begin{array}{l}\text { Not } \\
\text { reported }\end{array}$ & Not reported & $3.3 \%$ \\
\hline $\begin{array}{l}\text { Ajjimarungsi } \\
\text { et al. }^{54}\end{array}$ & 2006-2016 & Thailand & Single ICU & 23 & Not reported & Not reported & $\begin{array}{l}\text { Not } \\
\text { reported }\end{array}$ & $10(7-13)$ & $4.3 \%$ \\
\hline Delmas et al. ${ }^{55}$ & 2004-2015 & $\begin{array}{l}\text { Réunion } \\
\text { Island }\end{array}$ & Single ICU & 134 & Not reported & Not reported & $38(27-50)$ & $10(8-12)$ & $5.9 \%$ \\
\hline Miailhe et al. ${ }^{56}$ & 2012-2016 & France & $\begin{array}{l}\text { Multiple } \\
\text { ICU }\end{array}$ & 160 & Not reported & Not reported & $40(28-58)$ & $11(8-14)$ & $8.8 \%$ \\
\hline Tubiana et al. ${ }^{57}$ & 2008-2011 & $\begin{array}{c}\text { New } \\
\text { Caledonia }\end{array}$ & $\begin{array}{c}\text { Two } \\
\text { Hospitals, } \\
\text { Single ICU }\end{array}$ & 71 & Not reported & Not reported & $\begin{array}{l}\text { Not } \\
\text { reported }\end{array}$ & Not reported & $14.1 \%$ \\
\hline Abidi et al. ${ }^{58}$ & 2017 & Morocco & Single ICU & 100 & $12.5(6.1-18.9)$ & Not reported & $\begin{array}{c}24 \\
(12.5-35.5)\end{array}$ & Not reported & $23.0 \%$ \\
\hline Vandroux et al. ${ }^{59}$ & 2004-2017 & $\begin{array}{l}\text { Réunion } \\
\text { Island }\end{array}$ & Single ICU & $39^{\star}$ & Not reported & Not reported & $54(42-70)$ & $12(10-17)$ & $23.0 \%$ \\
\hline $\begin{array}{l}\text { De Francesco } \\
\text { Daher et al. }\end{array}$ & 2016 & Brazil & Single ICU & 83 & Not reported & Not reported & $\begin{array}{c}\text { Not } \\
\text { reported }\end{array}$ & Not reported & $23.5 \%$ \\
\hline Andrade et al. ${ }^{61}$ & 2002-2005 & Brazil & Single ICU & $33+$ & $\begin{array}{c}26 \\
(24.8-27.2) \ddagger \\
24.5(23.1-25.9)\end{array}$ & Not reported & $\begin{array}{l}\text { Not } \\
\text { reported }\end{array}$ & Not reported & $39.4 \%$ \\
\hline $\begin{array}{l}\text { Weeratunga } \\
\text { et al. }^{62}\end{array}$ & 2011-2014 & Sri Lanka & Single ICU & 45 & Not reported & Not reported & $\begin{array}{c}\text { Not } \\
\text { reported }\end{array}$ & Not reported & $44.4 \%$ \\
\hline $\begin{array}{l}\text { Vieira and } \\
\text { Brauner. }^{63}\end{array}$ & 1990-2000 & Brazil & Two ICU & 35 & $20.1 \pm 4.2 \S$ & Not reported & $\begin{array}{l}\text { Not } \\
\text { reported }\end{array}$ & Not reported & $51.4 \%$ \\
\hline Chawla et al. ${ }^{64}$ & 2002-2003 & India & Single ICU & 31 & Not reported & Not reported & $\begin{array}{l}\text { Not } \\
\text { reported }\end{array}$ & Not reported & $51.7 \%$ \\
\hline Marotto et al. ${ }^{65}$ & 1994-1997 & Brazil & Single ICU & 42 & Not reported" & Not reported & $\begin{array}{l}\text { Not } \\
\text { reported }\end{array}$ & Not reported & $54.7 \%$ \\
\hline
\end{tabular}

and even within-the countries where these infections are seen, routine reporting of SOI scores would provide more evidence to support this contention. ${ }^{3,24,78}$

Routine reporting of SOI scores-and their correlation with molecular characteristics of the pathogen-may also help determine the effect of geographic variation in the organisms' virulence on outcome. Phylogenetic analysis of melioidosis shows a clear distinction between Australian and South East Asian isolates and this may explain at least some of the difference in melioidosis-related mortality in the two continents. $^{79}$ Similarly, it has been postulated that differences in strains of $O$. tsutsugamushi contribute to the significant variation in clinical presentation of cases of scrub typhus. ${ }^{80}$ Specific serogroups are not believed to explain the different clinical presentations of leptospirosis, although some studies have suggested that particular serovars are more likely to cause severe disease. ${ }^{9,81,82}$ While the pathogens' virulence is likely to have a relatively modest effect on outcomes compared with access to optimal care, this issue remains incompletely defined. ${ }^{83,84}$

The reporting of SOl scores may also assist with the evaluation of therapeutic interventions in different cohorts. With advances in critical care, the mortality from sepsis continues to fall and this is also the case with many tropical infections. ${ }^{2}$ In a 24-year study of melioidosis in the Northern Territory of Australia, the case-fatality rate fell from $92.3 \%$ in 1989-1997 to $25.7 \%$ in $2005-2013$, which was attributed to changes in management strategies which included an intensivist-led model of care and the empiric use of meropenem. ${ }^{10}$ The reporting of SOI scores in this Northern Territory study facilitated an understanding of the severity of the cohort's illness and, therefore, the implications for other ICU with a significant burden of melioidosis. In addition, while there is a significant global burden of melioidosis, leptospirosis, and rickettsial disease, most of the published literature to examine these conditions are single-center studies; randomized controlled trials

TABLE 4

Severity of illness scores and case-fatality rates of patients with melioidosis admitted to the ICU in other case series

\begin{tabular}{|c|c|c|c|c|c|c|c|c|c|}
\hline Study & Study Period & Country & Setting & Cases & APACHE II & APACHE III & SAPS2 & SOFA & $\begin{array}{c}\text { ICU case-fatality } \\
\text { Rate } \%\end{array}$ \\
\hline Stephens et al. ${ }^{10}$ & 1989-2013 & Australia & Single ICU & 207 & $23 \pm 8.7^{*}$ & Not reported & Not reported & $8(5-11)$ & $33.8 \%$ \\
\hline Churuangsuk et al. ${ }^{66}$ & 2002-2011 & Thailand & Single ICU & 25 & Not reported & Not reported & Not reported & Not reported & $48 \%$ \\
\hline Chan et al. ${ }^{67}$ & 1996-2002 & Singapore & Multiple ICU & 27 & $27(9-47)$ & Not reported & Not reported & Not reported & $48.1 \%$ \\
\hline Tang et al. ${ }^{68}$ & 2013-2017 & Malaysia & Single ICU & 21 & Not reported & Not reported & Not reported & Not reported & $52.2 \%$ \\
\hline
\end{tabular}

* 
TABLE 5

Severity of illness scores and case-fatality rates of patients with rickettsial infection admitted to the ICU in other case series

\begin{tabular}{|c|c|c|c|c|c|c|c|c|c|}
\hline Study & Study Period & Country & Setting & Cases & APACHE ॥ & APACHE III & SAPS2 & SOFA & $\begin{array}{l}\text { ICU Case-fatality } \\
\text { Rate \% }\end{array}$ \\
\hline Sahoo et al. ${ }^{69}$ & 2013-2014 & India & Single ICU & 55 & $13.03 \pm 6.46$ & Not reported & Not reported & $6.64 \pm 3.72$ & $7.3 \%$ \\
\hline Moon et al. ${ }^{70}$ & 2004-2014 & South Korea & Single ICU & 70 & $14.9 \pm 4.8$ & Not reported & Not reported & $6 \pm 2.7$ & $14.3 \%$ \\
\hline Adhikari et al. ${ }^{71}$ & $2016-2017$ & Nepal & Single ICU & 120 & Not reported & Not reported & Not reported & Not reported & $20.0 \%$ \\
\hline Griffith et al. ${ }^{72}$ & 2008-2010 & India & Single ICU & 116 & $19.6 \pm 8.2$ & Not reported & Not reported & $10.5 \pm 3.9$ & $24.1 \%$ \\
\hline Lee et al. $^{73}$ & 2000-2006 & South Korea & Single ICU & $33^{*}$ & $\begin{array}{c}16.9 \pm 6.2 \\
8.3 \pm 4.8\end{array}$ & Not reported & Not reported & Not reported & $30.3 \%$ \\
\hline Lee et al. ${ }^{74}$ & 2001-2006 & South Korea & Single ICU & $23 \dagger$ & $\begin{array}{c}11.37 \pm 5.1 \\
6.94 \pm 4.2\end{array}$ & Not reported & Not reported & Not reported & $39.1 \%$ \\
\hline Moon et al. ${ }^{75}$ & 2004-2016 & South Korea & Single ICU & 91 & $15.4 \pm 6.1$ & Not reported & Not reported & $6.1 \pm 3.1$ & Not reported \\
\hline
\end{tabular}

are rare. This results in poorly powered, often retrospective studies whose conclusions are necessarily speculative. ${ }^{11,55}$ The use of SOI scores that stratify disease severity may help standardize recruitment of patients in multi-center trials that assess interventions more robustly.

This retrospective, single-center study has several important limitations. A relatively long, 22-year study period was used, but the sample size was small, limiting the study's power. The study only reflects clinical management strategies used at this center which evolved significantly over the study period. ${ }^{11,12}$ There were only 21 cases with rickettsial disease, and this group included patients with both scrub typhus and QTT, conditions caused by different pathogens. Some rickettsiologists may take issue with this approach. However, the infections have similar pathogenesis, presentation, and treatment and hence, from a pragmatic, clinical perspective we felt that it was reasonable to consider them together, although the findings may not be applicable to other rickettsial diseases. $^{8,30}$ A minority of the patients with rickettsial disease had a diagnosis confirmed by PCR or a 4-fold rise in serology; most $(8 / 21,62 \%)$ were diagnosed with a single serological titer. However, patients were only included in the study if they satisfied pre-specified, conservative criteria, similar to those used in the international literature. ${ }^{85-87}$ The hospital's ICU was expanded in 2016 to admit high dependency patients, which may have reduced the case-fatality rate seen in the cohort. However, as the SOI scores of these high dependency patients would tend to be lower as well, this would therefore not change the study's main finding. It could be argued that the study should have examined more contemporary scoring systems - such as the APACHE IV-which predicts mortality more accurately than the APACHE III. ${ }^{53}$ However, this score is not used in Australia and, as it uses 129 variables, it is unlikely to be calculated in the locations where melioidosis, leptospirosis, and rickettsial disease are seen most frequently. ${ }^{26}$ Finally, the scores were evaluated in Australia's well-resourced public health system and may not overestimate mortality to the same degree in less-resourced LMIC ICUs. However, this study provides a useful reference for researchers examining melioidosis, leptospirosis, and rickettsial disease in other locations and wishing to relate the outcomes seen in their cohorts to disease severity. ${ }^{25}$ As Tables 3-5 demonstrate the reporting of SOI scores in studies examining these pathogens is inconsistent, hindering understanding of geographical differences in the outcomes.

\section{CONCLUSION}

Commonly used SOI scores overestimated the casefatality rate of patients admitted to this Australian ICU with melioidosis, leptospirosis, and rickettsial disease. This may be at least partly explained by the distinctive pathophysiology of these infections, which inflates the scores, exaggerating the risk of death. However, there may still be utility in reporting SOI scores in clinical studies of these infections as comparison between cohorts may facilitate understanding of the relative contributions of host, pathogen, and access to care in the outcome of these globally important pathogens.

Received June 2, 2021. Accepted for publication August 31, 2021.

Published online October 18, 2021.

Note: Supplemental figure appears at www.ajtmh.org.

Acknowledgments: We would like to acknowledge all the clinicians involved in the care of the patients in this study and the support of the Australian New Zealand Intensive Care Society (ANZICS) who provided much of the raw data for the study.

Authors' addresses: Kris Salaveria, Yu-Hsuan Liu, and Markus Ott, Department of Intensive Care, Cairns Hospital, Cairns, Queensland, Australia, E-mails: kris.salaveria@health.qld.gov.au, yu-hsuan.liu@ health.qld.gov.au, and markus.ott@health.qld.gov.au. Simon Smith and Richard Bagshaw, Department of Medicine, Cairns Hospital, Cairns, Queensland, Australia, E-mails: simon.smith2@health.qld. gov.au and richard.bagshaw@health.qld.gov.au. Alexandra Stewart, Infectious Diseases Unit, Western Health, Victoria, Australia, E-mail: alexandra.stewart03@gmail.com. Matthew Law, Kirby Institute, University of New South Wales, Sydney, Australia, E-mail: mlaw@ kirby.unsw.edu.au. Angus Carter, Department of Intensive Care, Cairns Hospital, Cairns, Queensland, Australia, and James Cook University, Cairns Campus, Cairns, Queensland, Australia, E-mail: angus.carter@health.qld.gov.au. Josh Hanson, Department of Medicine, Cairns Hospital, Cairns, Queensland, Australia, and Kirby Institute, University of New South Wales, Sydney, NSW, Australia, E-mail: jhanson@kirby.unsw.edu.au.

\section{REFERENCES}

1. Rudd KE et al., 2020. Global, regional, and national sepsis incidence and mortality, 1990-2017: analysis for the Global Burden of Disease Study. Lancet 395: 200-211.

2. Kaukonen K-M, Bailey M, Suzuki S, Pilcher D, Bellomo R, 2014. Mortality related to severe sepsis and septic shock among critically ill patients in Australia and New Zealand, 2000-2012. JAMA 311: 1308-1316.

3. McGloughlin S, Richards GA, Nor MBM, Prayag S, Baker T, Amin P, 2018. Sepsis in tropical regions: report from the task force on tropical diseases by the World Federation of 
Societies of Intensive and Critical Care Medicine. J Crit Care 46: 115-118.

4. Davis JS, Cheng AC, McMillan M, Humphrey AB, Stephens DP, Anstey NM, 2011. Sepsis in the tropical top end of Australia's Northern Territory: disease burden and impact on Indigenous Australians. Med J Aust 194: 519-524.

5. Sundararajan V, Macisaac CM, Presneill JJ, Cade JF, Visvanathan K, 2005. Epidemiology of sepsis in Victoria, Australia. Crit Care Med 33: 71-80.

6. Hanson J, Smith S, Brooks J, Groch T, Sivalingam S, Curnow V, Carter A, Hargovan S, 2020. The applicability of commonly used predictive scoring systems in Indigenous Australians with sepsis: an observational study. Plos One 15: e0236339.

7. Smith S, Hanson J, Currie BJ, 2018. Melioidosis: an Australian perspective. Trop Med Infect Dis 3: 27.

8. Stewart AGA, Smith S, Binotto E, McBride WJH, Hanson J, 2019. The epidemiology and clinical features of rickettsial diseases in North Queensland, Australia: implications for patient identification and management. PLoS Negl Trop Dis 13: e0007583.

9. Smith S, Kennedy BJ, Dermedgoglou A, Poulgrain SS, Paavola MP, Minto TL, Luc M, Liu YH, Hanson J, 2019. A simple score to predict severe leptospirosis. PLoS Negl Trop Dis 13: e0007205.

10. Stephens DP, Thomas JH, Ward LM, Currie BJ, 2016. Melioidosis causing critical illness: a review of 24 years of experience from the Royal Darwin Hospital ICU. Crit Care Med 44: 1500-1505.

11. Smith S, Liu Y-H, Carter A, Kennedy BJ, Dermedgoglou A, Poulgrain SS, Paavola MP, Minto TL, Luc M, Hanson J, 2019. Severe leptospirosis in tropical Australia: optimising intensive care unit management to reduce mortality. PLoS Negl Trop Dis 13: e0007929-e0007929.

12. Bagshaw RJ, Stewart AGA, Smith S, Carter AW, Hanson J, 2020. The characteristics and clinical course of patients with scrub typhus and Queensland Tick Typhus infection requiring intensive care unit admission: a 23-year case series from Queensland, Tropical Australia. Am J Trop Med Hyg 103: 2472-2477.

13. Schneider AG, Lipcsey M, Bailey M, Pilcher DV, Bellomo R, 2013. Simple translational equations to compare illness severity scores in intensive care trials. J Crit Care 28: 885.e1885.e8.

14. Keegan MT, Gajic O, Afessa B, 2011. Severity of illness scoring systems in the intensive care unit. Crit Care Med 39: 163-169.

15. Knaus WA, Draper EA, Wagner DP, Zimmerman JE, 1985. APACHE II: a severity of disease classification system. Crit Care Med 13: 818-829.

16. Knaus WA et al., 1991. The APACHE III prognostic system. Risk prediction of hospital mortality for critically ill hospitalized adults. Chest 100: 1619-1636.

17. Vincent JL, Moreno R, Takala J, Willatts S, De Mendonca A, Bruining H, Reinhart CK, Suter PM, Thijs LG, 1996. The SOFA (Sepsis-related Organ Failure Assessment) score to describe organ dysfunction/failure. On behalf of the Working Group on Sepsis-Related Problems of the European Society of intensive care Medicine. Intensive Care Med 22: 707-710.

18. Le Gall JR, Lemeshow S, Saulnier F, 1993. A new simplified acute physiology score (SAPS II) based on a European/North American multicenter study. JAMA 270: 2957-2963.

19. Sadaka F, EthmaneAbouEIMaali C, Cytron MA, Fowler K, Javaux VM, O'Brien J, 2017. Predicting mortality of patients with sepsis: a comparison of APACHE II and APACHE III scoring systems. J Clin Med Res 9: 907-910.

20. Luo XP, Wang HH, Hu SF, Wu SJ, Xie GH, Cheng BL, Zhou C, Fang $\mathrm{XM}, 2009$. Comparison of three different organ failure assessment score systems in predicting outcome of severe sepsis. Zhonghua Wai Ke Za Zhi 47: 48-50.

21. Singh P, Pathak S, Sharma RM, 2018. A comparison of acute physiology and chronic health evaluation III and simplified acute physiology score II in predicting sepsis outcome in intensive care unit. Anesth Essays Res 12: 592-597.

22. Khwannimit B, Bhurayanontachai R, Vattanavanit V, 2018. Comparison of the performance of SOFA, QSOFA and SIRS for predicting mortality and organ failure among sepsis patients admitted to the intensive care unit in a middle-income country. J Crit Care 44: 156-160.
23. Raith EP, Udy AA, Bailey M, McGloughlin S, Maclsaac C, Bellomo R, Pilcher DV, 2017. Prognostic accuracy of the SOFA score, SIRS criteria, and qSOFA score for in-hospital mortality among adults with suspected infection admitted to the intensive care unit. JAMA 317: 290-300.

24. Thwaites CL et al., 2019. Infection management in patients with sepsis and septic shock in resource-limited settings. Dondorp AM, Dunser MW, Schultz MJ, eds. Sepsis Management in Resource-Limited Settings. Cham, 163-184.

25. Haniffa R, Isaam I, De Silva AP, Dondorp AM, De Keizer NF, 2018. Performance of critical care prognostic scoring systems in low and middle-income countries: a systematic review. Crit Care 22: 18.

26. Haniffa $R$ et al., 2017. Applicability of the APACHE II model to a lower middle income country. J Crit Care 42: 178-183.

27. Stewart JD, Smith S, Binotto E, McBride WJ, Currie BJ, Hanson $\mathrm{J}, 2017$. The epidemiology and clinical features of melioidosis in far North Queensland: implications for patient management. PLoS Negl Trop Dis 11: e0005411.

28. Limmathurotsakul D et al., 2016. Predicted global distribution of Burkholderia pseudomallei and burden of melioidosis. Nat Microbiol 1: 15008.

29. Torgerson PR, Hagan JE, Costa F, Calcagno J, Kane M, Martinez-Silveira MS, Goris MG, Stein C, Ko Al, Abela-Ridder B, 2015. Global burden of leptospirosis: estimated in terms of disability adjusted life years. PLoS Negl Trop Dis 9: e0004122.

30. Brezina R, Murray ES, Tarizzo ML, Bogel K, 1973. Rickettsiae and rickettsial diseases. Bull World Health Organ 49: 433-442.

31. 2004. Australian National Notifiable Diseases Case Definitions-Leptospirosis. Available at: www.health.gov.au/internet/ main/publishing.nsf/Content/cda-surveil-nndss-casedefs-cd lepto.htm. Accessed April 1, 2021.

32. Society AaNZIC, 2020. Severity Score and Risk of Death Calculators. Available at: https://www.anzics.com.au/severity-scoreand-risk-of-death-calculators/. Accessed September 32020.

33. Medlej K, 2020. Sequential Organ Failure Assessment (SOFA) Score. Available at: https://www.mdcalc.com/sequentialorgan-failure-assessment-sofa-score. Accessed September 21, 2020.

34. 2021. Severity Score and Risk of Death Calculators. Available at: https://www.anzics.com.au/severity-score-and-risk-of-deathcalculators/. Accessed December 1, 2020.

35. Nassar AP Jr., Mocelin AO, Nunes AL, Giannini FP, Brauer L, Andrade FM, Dias CA, 2012. Caution when using prognostic models: a prospective comparison of 3 recent prognostic models. J Crit Care 27: 423.e1-e7.

36. Moreno RP, Nassar AP Jr., 2017. Is APACHE II a useful tool for clinical research? Rev Bras Ter Intensiva 29: 264-267.

37. Escarce JJ, Kelley MA, 1990. Admission source to the medical intensive care unit predicts hospital death independent of APACHE II score. JAMA 264: 2389-2394.

38. Metnitz PG et al., 2005. SAPS 3-from evaluation of the patient to evaluation of the intensive care unit. Part 1: objectives, methods and cohort description. Intensive Care Med 31: 1336-1344.

39. De Brito T, Silva A, Abreu PAE, 2018. Pathology and pathogenesis of human leptospirosis: a commented review. Rev Inst Med Trop São Paulo 60: e23.

40. Diaz FE, Abarca K, Kalergis AM, 2018. An update on hostpathogen interplay and modulation of immune responses during Orientia tsutsugamushi infection. Clin Microbiol Rev 31: e00076-17.

41. Feng HM, Wen J, Walker $\mathrm{DH}, 1993$. Rickettsia australis infection: a murine model of a highly invasive vasculopathic rickettsiosis. Am J Pathol 142: 1471-1482.

42. Stephens JR, Stumpfle R, Patel P, Brett S, Broomhead R, Baharlo B, Soni S, 2021. Analysis of critical care severity of illness scoring systems in patients with coronavirus disease 2019: a retrospective analysis of three U.K. ICUs. Crit Care Med 49: e105-e107.

43. Daher EF et al., 2014. Factors associated with thrombocytopenia in severe leptospirosis (Weil's disease). Clinics (São Paulo) 69: $106-110$ 
44. Panaphut T, Domrongkitchaiporn S, Thinkamrop B, 2002. Prognostic factors of death in leptospirosis: a prospective cohort study in Khon Kaen, Thailand. Int J Infect Dis 6: 52-59.

45. Sriwongpan $P$, Krittigamas $P$, Kantipong $P$, Kunyanone N, Patumanond J, Namwongprom S, 2013. Clinical indicators for severe prognosis of scrub typhus. Risk Manag Healthc Policy 6: 43-49.

46. Varghese GM, Abraham OC, Mathai D, Thomas K, Aaron R, Kavitha ML, Mathai E, 2006. Scrub typhus among hospitalised patients with febrile illness in South India: magnitude and clinical predictors. J Infect 52: 56-60.

47. Gassiep I, Armstrong M, Norton R, 2020. Human melioidosis. Clin Microbiol Rev 33: e00006-e00019.

48. Bouch DC, Thompson JP, 2008. Severity scoring systems in the critically ill. Contin Educ Anaesth Crit Care Pain 8: 181-185.

49. Moreno RP, 2008. Outcome prediction in intensive care: why we need to reinvent the wheel. Curr Opin Crit Care 14: 483-484.

50. Lewinsohn G, Herman A, Leonov Y, Klinowski E, 1994. Critically ill obstetrical patients: outcome and predictability. Crit Care Med 22: 1412-1414.

51. Nassar AP, Malbouisson LM, Moreno R, 2014. Evaluation of simplified acute physiology score 3 performance: a systematic review of external validation studies. Crit Care 18: R117.

52. Zimmerman JE, Kramer AA, McNair DS, Malila FM, 2006. Acute physiology and chronic health evaluation (APACHE) IV: hospital mortality assessment for today's critically ill patients. Crit Care Med 34: 1297-1310.

53. Cedano J, Rodríguez S, Kujundzic W, Arana JS, Pacheco R, Rosso F, 2019. Clinical characterization of patients with severe leptospirosis in a tertiary hospital in Cali, Colombia, 2010-2016. Biomedica 39: 108-116.

54. Ajjimarungsi A, Bhurayanontachai R, Chusri S, 2020. Clinical characteristics, outcomes, and predictors of leptospirosis in patients admitted to the medical intensive care unit: a retrospective analysis. J Infect Public Health 13: 2055-2061.

55. Delmas B, Jabot J, Chanareille P, Ferdynus C, Allyn J, Allou N, Raffray L, Gaüzere BA, Martinet O, Vandroux D, 2018. Leptospirosis in ICU: a retrospective study of 134 consecutive admissions. Crit Care Med 46: 93-99.

56. Miailhe AF et al., 2019. Severe leptospirosis in non-tropical areas: a nationwide, multicentre, retrospective study in French ICUs. Intensive Care Med 45: 1763-1773.

57. Tubiana S, Mikulski M, Becam J, Lacassin F, Lefèvre P, Gourinat AC, Goarant C, D'Ortenzio E, 2013. Risk factors and predictors of severe leptospirosis in New Caledonia. PLoS Negl Trop Dis 7: e1991.

58. Abidi K, Dendane T, Madani N, Belayachi J, Abouqal R, Zeggwagh AA, 2017. The clinical picture of severe leptospirosis in critically ill patients. Intensive Care Med 43: 1740-1741.

59. Vandroux D, Chanareille P, Delmas B, Gaüzère BA, Allou N, Raffray L, Jaffar-Bandjee MC, Martinet O, Ferdynus C, Jabot J, 2019. Acute respiratory distress syndrome in leptospirosis. J Crit Care 51: 165-169.

60. Daher Ede F, Soares DS, de Menezes Fernandes AT, Girão MM, Sidrim PR, Pereira ED, Rocha NA, da Silva GB Jr., 2016. Risk factors for intensive care unit admission in patients with severe leptospirosis: a comparative study according to patients' severity. BMC Infect Dis 16: 40.

61. Andrade L, Cleto S, Seguro AC, 2007. Door-to-dialysis time and daily hemodialysis in patients with leptospirosis: impact on mortality. Clin J Am Soc Nephrol 2: 739-744.

62. Weeratunga PN, Fernando S, Sriharan S, Gunawardena M, Wijenayake S, 2015. Determinants of mortality and impact of therapy in patients with leptospirosis admitted for intensive care in a Sri Lankan hospital-a three year retrospective study. Pathog Glob Health 109: 387-394.

63. Vieira SR, Brauner JS, 2002. Leptospirosis as a cause of acute respiratory failure: clinical features and outcome in 35 critical care patients. Braz J Infect Dis 6: 135-139.

64. Chawla V, Trivedi TH, Yeolekar ME, 2004. Epidemic of leptospirosis: an ICU experience. J Assoc Physicians India 52: 619-622.

65. Marotto PCF, Nascimento CMR, Eluf-Neto J, Marotto MS, Andrade L, Sztajnbok J, Seguro AC, 1999. Acute lung injury in leptospirosis: clinical and laboratory features, outcome, and factors associated with mortality. Clin Infect Dis 29: 1561-1563.

66. Churuangsuk C, Chusri S, Hortiwakul T, Charernmak B, Silpapojakul K, 2016. Characteristics, clinical outcomes and factors influencing mortality of patients with melioidosis in southern Thailand: a 10-year retrospective study. Asian Pac J Trop Med 9: 256-260.

67. Chan KP, Low JG, Raghuram J, Fook-Chong SM, Kurup A, 2005. Clinical characteristics and outcome of severe melioidosis requiring intensive care. Chest 128: 3674-3678.

68. Tang RY, Lim SH, Lam JE, Nurasykin S, Eileen T, Chan YW, 2019. A 5-year retrospective study of melioidosis cases treated in a district specialist hospital. Med J Malaysia 74: 472-476.

69. Sahoo JN, Gurjar M, Harde Y, 2016. Acute respiratory failure in scrub typhus patients. Indian J Crit Care Med 20: 480-484.

70. Moon KM, Han MS, Rim CB, Lee JH, Kang MS, Kim JH, Kim SI, Jung SY, Cho Y, 2016. Risk factors for mechanical ventilation in patients with scrub typhus admitted to intensive care unit at a university hospital. Tuberc Respir Dis (Seoul) 79: 31-36.

71. Adhikari S, Poudel RS, Shrestha S, Lamichhane P, 2018. Predictors of mortality in scrub typhus infection requiring intensive care admission in tertiary healthcare centre of Nepal. Interdiscip Perspect Infect Dis 2018: 4867958.

72. Griffith $\mathrm{M}$ et al., 2014. Profile of organ dysfunction and predictors of mortality in severe scrub typhus infection requiring intensive care admission. Indian J Crit Care Med 18: 497-502.

73. Lee CS, Hwang JH, Lee HB, Kwon KS, 2009. Risk factors leading to fatal outcome in scrub typhus patients. Am J Trop Med Hyg 81: 484-488.

74. Lee CS, Min IS, Hwang JH, Kwon KS, Lee HB, 2010. Clinical significance of hypoalbuminemia in outcome of patients with scrub typhus. BMC Infect Dis 10: 216.

75. Moon KM, Min KW, Kim MH, Kim DH, Son BK, Oh Y, Jung W, Kwon M, Kwon OY, 2019. Higher acid-base imbalance associated with respiratory failure could decrease the survival of patients with scrub typhus during intensive care unit stay: a gene set enrichment analysis. J Clin Med 8: 1580.

76. Walker DH, Fishbein DB, 1991. Epidemiology of rickettsial diseases. Eur J Epidemiol 7: 237-245.

77. Shenoy VV, Nagar VS, Chowdhury AA, Bhalgat PS, Juvale NI, 2006. Pulmonary leptospirosis: an excellent response to bolus methylprednisolone. Postgrad Med J 82: 602-606.

78. Smith S, Hanson J, 2020. Improving the mortality of severe leptospirosis. Intensive Care Med 46: 827-828.

79. Wiersinga WJ, Virk HS, Torres AG, Currie BJ, Peacock SJ, Dance DAB, Limmathurotsakul D, 2018. Melioidosis. Nat Rev Dis Primers 4: 17107.

80. Kelly DJ, Fuerst PA, Ching WM, Richards AL, 2009. Scrub typhus: the geographic distribution of phenotypic and genotypic variants of Orientia tsutsugamushi. Clin Infect Dis 48: S203-S230.

81. Wang HK, Lee MH, Chen YC, Hsueh PR, Chang SC, 2020. Factors associated with severity and mortality in patients with confirmed leptospirosis at a regional hospital in northern Taiwan. J Microbiol Immunol Infect 53: 307-314.

82. Levett PN, 2001. Leptospirosis. Clin Microbiol Rev 14: 296-326.

83. Smith S, Stewart JD, Tacon C, Archer N, Hanson J, 2017. Children with melioidosis in far North Queensland are commonly bacteraemic and have a high case fatality rate. Commun Dis Intell Q Rep 41: E318-E321.

84. Sarovich DS, Price EP, Webb JR, Ward LM, Voutsinos MY, Tuanyok A, Mayo M, Kaestli M, Currie BJ, 2014. Variable virulence factors in Burkholderia pseudomallei (melioidosis) associated with human disease. PLOS ONE 9: e91682.

85. Lee $\mathrm{N}$ et al., 2008. Risk factors associated with life-threatening rickettsial infections. Am J Trop Med Hyg 78: 973-978.

86. Holman RC, Paddock CD, Curns AT, Krebs JW, McQuiston JH, Childs JE, 2001. Analysis of risk factors for fatal rocky mountain spotted fever: evidence for superiority of tetracyclines for therapy. J Infect Dis 184: 1437-1444.

87. Stewart A, Armstrong M, Graves S, Hajkowicz K, 2017. Clinical manifestations and outcomes of Rickettsia australis infection: a 15-year retrospective study of hospitalized patients. Trop Med Infect Dis 2: 19. 